\title{
Is coral richness related to community resistance to and recovery from disturbance?
}

More diverse communities are thought to be more stable - the diversity-stability hypothesis due to increased resistance to and recovery from disturbances. For example, high diversity can make the presence of resilient or fast growing species and key facilitations among species more likely. How natural geographic biodiversity patterns and changes in biodiversity due to human activities mediate community-level disturbance dynamics is largely unknown, especially in diverse systems. For example, few studies have explored the role of diversity in tropical marine communities, especially at large scales. We tested the diversity-stability hypothesis by asking whether coral richness is related to resistance to and recovery from disturbances including storms, predator outbreaks, and coral bleaching on tropical coral reefs. We synthesized the results of 41 field studies conducted on 82 reefs, documenting changes in coral cover due to disturbance, across a global gradient of coral richness. Our results indicate that coral reefs in more species rich regions were marginally less resistant to disturbance and did not recover more quickly. Coral community resistance was also highly dependent on pre-disturbance coral cover, probably due in part to the sensitivity of fastgrowing and often dominant plating acroporid corals to disturbance. Our results suggest that coral communities in biodiverse regions such as the western Pacific may not be more resistant to natural and anthropogenic disturbances. Further analyses controlling for disturbance intensity and other drivers of coral loss and recovery could improve our understanding of the influence of diversity on community stability in coral reef ecosystems. 
2 Stacy Y. Zhang ${ }^{1}$, Speare, Kelly E. ${ }^{1}$; Long, Zachary T. ${ }^{2}$; McKeever, Kimberly A. ${ }^{1}$; Gyoerkoe,

3 Megan ${ }^{1}$; Ramus, Aaron P., ${ }^{1,2,}$; Mohorn, Zach ${ }^{1 ;}$ Akins, Kelsey L. ${ }^{1}$; Hambridge, Sarah M. ${ }^{1}$; Graham,

4 Nicholas A. J. ${ }^{3}$; Nash, Kirsty L. ${ }^{3}$; Selig, Elizabeth, R. ${ }^{4}$, Bruno, John F. ${ }^{*}$

$5 \quad{ }^{1}$ Department of Biology, The University of North Carolina at Chapel Hill, Chapel Hill, NC $6 \quad$ 27599-3300 USA

7 2Department of Biology and Marine Biology, University of North Carolina at Wilmington,

8 Wilmington, NC 28403 USA

$9 \quad{ }^{3}$ Australian Research Council Centre of Excellence for Coral Reef Studies, James Cook

10 University, Townsville, QLD 4811, Australia

$11{ }^{4}$ The Betty and Gordon Moore Center for Ecosystem Science and Economics, Conservation

12 International, 2011 Crystal Drive, Suite 500, Arlington, VA 22202

13 *Corresponding author: jbruno@unc.edu 


\section{Introduction}

A large body of recent and classical ecological research has focused on how biodiversity influences the stability of communities (May 1973; McCann 2000; Pimm 1984; Hughes and Stachowicz 2004; Steiner et al. 2006; Cardinale et al. 2012). Despite this interest, there is still no consensus on whether or why diversity influences stability. This may be due in part to the multitude of ways stability has been defined (Grimm \& Wissel 1997; McCann 2000; $\underline{\text { Pimm }}$ 1984). Here, we define community stability as the ability to maintain a given state regardless of perturbation, invasion, or extinction (McCann 2000). Mechanistically, stability is made up of two components: resistance - the degree to which a community changes in response to a disturbance, and recovery or "resilience" - the rate of return to pre-disturbance conditions ( 1997; Ives \& Carpenter 2007; May 1973; McCann 2000).

Species richness (the number of species within an area) is thought to influence community stability via several mechanisms (Ives et al. 2005). For example, species rich communities are more likely, due to chance alone, to include greater functional diversity, and redundancy of function within functional groups - the insurance hypothesis (McNaughton 1977; Tilman \& Downing 1994). The inclusion of species that can tolerate or benefit from disturbance could increase community resistance (McCann 2000; Tilman \& Downing 1994; Yachi \& Loreau 1999). Additionally, positive feedbacks among species via facilitation may be more common in diverse communities, which may enhance post-disturbance recovery (Naeem 1998; Naeem \& Li 1997; Yachi \& Loreau 1999).

Understanding the role of species richness in community stability has been a focus of a number of field studies and meta-analyses (Duffy et al. 2001; Ives \& Carpenter 2007; Stachowicz et al. 2007; Stachowicz et al. 2008; Cardinale et al. 2012). Some experimental studies in terrestrial plant communities have found a positive relationship between species richness and stability (Ives \& Carpenter 2007; Tilman \& Downing 1994). For example, more diverse plant 
communities appear to be more resistant to disturbances including drought (Tilman \& Downing 1994). Manipulations of marine plant and invertebrate community richness have found that diversity is positively related to resistance and recovery (Stachowicz et al. 2007). Likewise, Boyer et al. (2009) experimentally demonstrated that species-rich algal communities were more resistant to disturbances than species-poor communities in estuarine ecosystems of eastern North Carolina. One of the few large scale tests of the diversity-stability concept was a study of boreal forest communities in north-western Quebec (Grandpre et al. 1997), which found that greater species-richness conferred more resistance to changes in community composition and abundance following a disturbance.

We tested the hypothesis that species richness is related to community stability (resistance and recovery) in coral reef ecosystems. Coral communities are affected by a large range of natural and anthropogenic disturbances including storms, disease outbreaks, coral bleaching due to ocean warming, dynamite fishing, and predator outbreaks (e.g., Acanthaster planci or Crown-of-Thorns Starfish (COTS)). A recent study of coral-community recovery found that disturbance type, e.g., "physical" vs. "biological" disturbances, and other reef characteristics had little effect on recovery rate; although, recovery was influenced by post-disturbance coral cover, geographic region, and reef management (Graham et al. 2011). We expanded on this work by asking whether coral richness is related to resistance to and or recovery from disturbances at a large spatio-temporal scale using coral cover as a metric of reef state. We hypothesized that coral communities in species rich regions would exhibit greater resistance and recovery in response to disturbances. We synthesized the results of 41 field studies documenting post-disturbance changes in coral cover across a natural gradient of coral richness. 
Our analyses were based on an expanded version of the coral cover change database compiled by Graham et al. (2011). We added 18 new studies (35 additional reefs), resulting in a total of 82 reefs (Text S1). Twenty-eight studies were used in the decline analyses, and 30 were included in the recovery analyses, with many studies providing both resistance and recovery data. We identified and added studies that quantitatively documented community responses following disturbances, both losses and recoveries, in percentage of benthos covered by living coral species on subtidal reefs $(0.5-40 \mathrm{~m}$ depth, median survey depth $=10 \mathrm{~m})$. If component values were in a graphical format, ImageJ software was used to extract values for analysis. Survey locations were categorized into four regions: Eastern Pacific, Western Pacific, Indian Ocean, and Caribbean (Fig. S1). In addition to browsing relevant coral reef and ecology journals, we also used online academic search tools (e.g., Google Scholar, ISI Web of Science) to search for published peerreviewed sources of coral-cover change data using the search terms: "disturbance," "coral cover," “Acanthaster planci," "bleaching," "storm," “cyclone," "hurricane," "resistance," "resilience," "recovery," and "richness."

Studies had to meet four criteria to be included in the present analysis (Graham et al. 2011). 1) A clear description of sampling methods. Most surveys were performed using a variation of the line transect method where a $10-30 \mathrm{~m}$ transect is placed on the reef and coral cover is estimated either in situ or from digital images or videos. Although manta tow data can be unbiased if extensive training is involved (Miller \& Müller 1999), all manta tow data was excluded because we were unable to verify the accuracy of the majority of manta tow surveys performed. 2) Documented changes in coral cover due to one of three types of disturbance: Acanthaster planci outbreaks, coral bleaching, and storm (hurricanes and cyclones) impacts. Other disturbances such as dynamite fishing and ship groundings were not included due to a lack of studies and the small scale of disturbance. 3) Changes in hard coral cover were documented for resistance: pre-disturbance (initial cover) and immediately after disturbance (remnant cover); or 
recovery: remnant cover and peak recorded cover post-disturbance (peak recovery). Where peak recovery was assessed, post-disturbance cover was monitored for at least 3 years following disturbance. 4) Coral cover decreased at least $10 \%$ relative to pre-disturbance cover due to disturbance (Eqn. 1).

Initial cover - Post disturbance cover $\geq 0.1$ ( Initial cover) (Eqn. 1)

We excluded studies in which the change in coral cover was $<10 \%$ relative to initial coral cover because such relatively small year to year changes cannot be reliably distinguished from random noise, e.g., stochastic variation and sampling error. Benthic survey methodologies rarely are able to detect changes in cover $<5-10 \%$. Graham 2011 et al. used a similar justification for excluding such studies: "the initial drop in coral cover as a result of the disturbance exceeded $10 \%$. Studies recording lower initial mortality were excluded as small disturbances may have negligible impact on hard coral cover (e.g., Edmunds 2002). Furthermore, inter-annual variation in coral cover can be $\sim 5 \%$ prior to a disturbance (e.g., Halford et al. 2004). A $10 \%$ relative decline reflects a sudden change in benthic cover in response to a pulse disturbance." However, in contrast to Graham et al. 2011, we chose a 10\% relative decline as a cutoff to account for disturbances that cause little absolute change but may in fact have a proportionally significant impact to reefs, particularly those with low levels of initial coral cover.

Predicted coral richness values in our analyses are geographic estimates based on coral

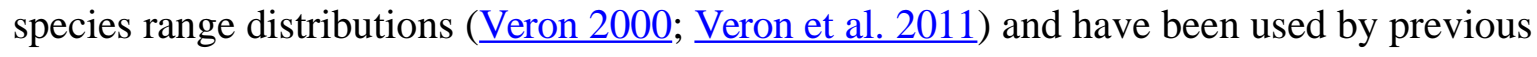
studies (e.g., Roberts et al. (2002); Veron et al. (2009)). Maps were originally vector data, but we gridded them to a resolution of $50 \mathrm{~km}$. The coral richness predictions that result from this database are relatively coarse-grained, however, given the strong association between local and regional coral richness (Karlson et al. 2004), our richness values likely correspond in a relative sense to local richness at a site. 


\section{Statistical Analysis}

We used the R programming environment ( $\underline{\mathrm{R} \text { Core Team 2012) }}$ to perform two separate sets of regression analyses to test whether predicted coral richness was related to coral community resistance to and recovery from disturbance. Variance inflation factors (VIFs) were calculated for each pair of predictors to test for collinearity in both sets of analyses. The initial model for decline included predicted coral richness, initial (pre-disturbance) coral cover, maximum survey depth, region, and disturbance type as predictors. Initial predictors for recovery rate included predicted coral richness, post-disturbance coral cover, maximum survey depth, region, and disturbance type. We incrementally and individually removed non-significant predictors from the models using backwards stepwise elimination. Akaike Information Criteria (AIC) was used in model selection to assess which model provided the best fit. Decline (resistance) analyses were performed using square root transformed net absolute coral loss, and in the recovery analysis, we used log transformed recovery rate, calculated as the change in coral cover, generally an increase, divided by the number of years until peak coral cover was observed (Eqn 2).

$$
\log \left(\frac{\text { peak recorded recovery }- \text { post-disturbance cover }}{\text { peak recovery year }- \text { post-disturbanc year }} \div \text { Eqn. } 2\right.
$$

In cases where recovery was not observed and reefs continued to decline i.e. negative recovery, recovery rate was equated to zero. Transformations were based on the distribution of the raw data. All models were also performed on raw data, the results of which did not different qualitatively from those based on transformed data. The core database (including all response and predictor variables), the $\mathrm{R}$ code, and model outputs were made available for editors and reviewers upon manuscript resubmission and will remain available for future readers. We did this to enable our analysis to be reproduced, to be as open as possible about our procedures, and to facilitate future analysis based on our database. 


\section{Results}

There was substantial variation among sites in predicted coral richness (24-552 species, Fig. 1), coral cover loss (Fig. 1), and recovery rate (Fig. 2). The full linear regression model testing the null hypothesis that coral species richness was not related to (sqrt transformed) post-disturbance coral cover loss (decline) found that all covariates (including richness; $p=0.79$ ) except predisturbance coral cover (blcc, $\mathrm{p}<0.0001$ ) were unrelated to decline (Fig. S2, Table 1, Model 1, Adj. $\mathrm{R}^{2}=0.63$, see all model results and $\mathrm{R}$ code in the Statistical Supplement). A simpler model (Model 2, Adj. $\mathrm{R}^{2}=0.60$ ) that included three covariates (depth, richness, and blcc) with a similar fit indicated that the richness effect was marginally significant $(\mathrm{p}=0.03)$. There was no relationship (Adj. $\mathrm{R}^{2}=0.01, \mathrm{p}=0.50$ ) between predicted coral richness and initial cover, thus it is unlikely that collinearity between these two covariates led to the putative effects of richness on resistance. When we removed sites (two potential outliers) with extreme decline and high diversity, the relationship between relative decline and predicted species richness was still significant (in the reduced model with three covariates).

The full recovery model (Table 1 , Model 4 in the Statistical Supplement, Adj. $R^{2}=0.26$ ) was the best fit and indicated that none of the covariates were related to recovery rate. Predicted coral richness in particular appeared a very poor predictor of coral recovery rate $(\mathrm{p}=0.56)$.

\section{Discussion}

We did not detect an effect of region, disturbance type or depth on absolute loss in coral cover due to disturbance (Table 1, Statistical Supplement). There was a weak positive relationship between predicted species richness and coral loss (Fig. 1). However, a richness effect $(\mathrm{p}=0.03)$ was only detected in the reduced model (Model 2), from which maximum depth, region, and 
disturbance type were removed (Statistical Supplement). In the full model with all five covariates (Model 1), the richness effect was not significant $(\mathrm{p}=0.79)$.

Concordant with several previous studies (Graham et al. 2008; Selig \& Bruno 2010; Selig et al. 2012), reefs with greater initial cover lost the most coral following disturbance (Fig. 1, Statistical Supplement). This could be due in part to the dominance of high cover reefs in the western Pacific and Indian ocean by plating acroporid corals, that are especially sensitive to both physical and biological disturbances (Darling et al. 2012), i.e., not due to a cover effect per se, but instead to the relationship, both among reefs and regions, between coral cover and species composition. Acroporids are among the most sensitive coral species to most of the disturbances known to cause declines in coral cover, e.g., thermal stress, disease, predation, and physical disturbance (Bruno et al. 2001; Darling et al. 2012; Willis et al. 2004). Therefore reefs dominated by plating and branching acroporids - the highest cover reefs - are likely to be especially susceptible to disturbance. Although high taxonomic richness may confer greater functional diversity and redundancy, this also implies a greater number of specialists that may not be well adapted to disturbance or stressful conditions (Dobzhansky 1950; $\underline{\text { Schluter 2000) }}$ and may partially explain our results. In fact, Côté and Darling (2010) argued that managing for coral cover could counter-intuitively make reefs more susceptible to disturbances including climate change.

Unlike several previous experimental studies in marine systems ( $\underline{\text { Allison 2004; }}$ Reusch et al. 2005; Williams 2001), our mensurative study found that the rate of post-disturbance recovery was not significantly related to taxonomic richness (Table 1, Fig. 2). The large observed variance in recovery rate among sites and studies (up to $12.5 \%$ per year) appears to be due to factors not included in our model and unrelated to estimated species richness.

Graham et al. (2011) reported that coral recovery varied somewhat among regions, with the highest observed recovery rates in the western Pacific, the most species rich region, (Roberts 
et al. 2002). Despite that finding, in our analysis coral richness was a poor predictor of recovery rate (Fig. 2); although, the low richness reefs of the eastern Pacific recovered slowly, recovery of Caribbean reefs with similar richness was greater and similar to that seen in the more diverse western Pacific and Indian ocean (Fig. 2). This finding could be due in part to a publication biases towards studies that document recovery and the fact that we searched for studies documenting acute disturbances, whereas chronic perturbations are also responsible for Caribbean coral losses. Furthermore, studies conducted in the eastern Pacific and included in our analysis were mostly conducted on reefs dominated by slow-growing, massive Porites. Given the current state of the Caribbean (Bruno et al. 2009) there is no doubt that coral cover on most Caribbean reefs has not recovered from various natural and anthropogenic disturbances over the last several decades (Roff and Mumby 2012). Hence, our results suggest that low diversity Caribbean reefs have the potential to recover (in terms of coral cover) quite rapidly (e.g., Idjadi et al. 2006), but for a variety of reasons they rarely do (Roff and Mumby 2012).

The majority of reefs in our study were monitored for less than eight years and few were monitored long enough to recover fully (Fig. S3), given observed rates in recovery. Of the 23 reefs for which we had both initial post-disturbance and peak-year coral cover, only five (all monitored for at least 11 years after disturbance) recovered to pre-disturbance levels of cover. If recovery (coral cover increase) is indeed non-linear over time, we could have seen different results, e.g., a significant richness effect if the component studies were conducted longer. To a degree, our results could also be an artifact of the loss of Acroporid corals from Caribbean reefs in the 1980 s, due primarily to disease but in some locations to storms and predation (Aronson \& Precht 2006). Our earliest Caribbean recovery study began in 1987 (Edmunds 2002), after Acroporid populations had crashed regionally (Aronson \& Precht 2006). Had Acropora cervicornis and A. palmata been present on Caribbean reefs when the datasets used in our analyses were collected, we might have seen more rapid recovery on low diversity reefs because 
these corals were amongst the fastest growing corals in the Caribbean region. However, we may also have seen even less resistance to disturbance due to their high coral cover and vulnerability to various stressors.

It is possible that systematic variation in disturbance intensity could obscure a richness effect on coral community resistance. For example, disturbance intensity may have co-varied with coral richness or peak coral cover. Although quantification of the intensity of disturbance is beyond the scope of this study, it would, at least in theory, be possible. Our study also addresses a very large scale richness gradient but ignores smaller scale variation, e.g., among reefs or zones (Huston 1985). Furthermore, we used predicted richness values from known biogeographic ranges (Veron 2000, Veron et al. 2011), which should reflect patterns of richness at this scale, but can make richness and region hard to tease apart and cannot account for local site level differences due to factors such as reef zone, disturbance history, micro-climates. Diversity of fish assemblages may also be critical for coral recovery dynamics (Bellwood et al. 2004), which was not considered in this study. Future analyses with empirical diversity data of corals and fish, controlling for disturbance intensity and other drivers of coral loss and recovery, could improve our understanding of the influence of diversity on community stability in coral reef ecosystems. 
224

225

226

227

228

229

230

231

232

Allison G. 2004. The influence of species diversity and stress intensity on community resistance and resilience. Ecological Monographs 74:117-134.

Aronson RB, and Precht WF. 2001. White-band disease and the changing face of Caribbean coral reefs. Hydrobiologia 460:25-38.

Aronson RB, and Precht WF. 2006. Conservation, precaution, and Caribbean reefs. Coral Reefs 25:441-450.

Bellwood, DR, TP Hughes, C. Folke, M. Nyström. 2004. Confronting the coral reef crisis. Nature 429: $827-833$

Boyer KE, Kertesz JS, and Bruno JF. 2009. Environmental context influences the effects of species richness on productivity but not stability of marine macroalgal communities. Oikos 118:1062-1072.

Bruno JF, Siddon CE, Witman JD, Colin PL, and Toscano MA. 2001. El Niño related coral bleaching in Palau, Western Caroline Islands. Coral Reefs 20:127-136.

Bruno, J. F., and E. R. Selig. 2007. Regional decline of coral cover in the Indo-Pacific: timing, extent, and subregional comparisons. PLoS One:e711.

Bruno JF, Sweatman H, Precht WF, Selig ER, and Schutte VGW. 2009. Assessing evidence of phase shifts from coral to macroalgal dominance on coral reefs. Ecology 90:1478-1484.

Cardinale BJ, Duffy JE, Gonzalez A, Hooper DU, Perrings C, Venail P, Narwani A, Mace GM, Tilman D et al. 2012. Biodiversity loss and its imp[act on humanity. Nature 486: 59-67.

Côté IM, and Darling ES. 2010. Rethinking ecosystem resilience in the face of climate change. PLoS Biol 8:e1000438.

Darling ES, Alvarez-Filip L, Oliver TA, McClanahan TR, and Côté IM. 2012. Evaluating lifehistory strategies of reef corals from species traits. Ecology Letters 15:1378-1386.

Dobzhansky T. 1950. Evolution in the tropics. American Scientist 38:209-221. 
Duffy JE, Macdonald KS, Rhode JM, and Parker JD. 2001. Grazer diversity, functional redundancy, and productivity in seagrass beds: an experimental test. Ecology 82:24172434.

Edmunds PJ. 2002. Long-term dynamics of coral reefs in St. John, US Virgin Islands. Coral Reefs 21:357-367.

Graham N, Nash K, and Kool J. 2011. Coral reef recovery dynamics in a changing world. Coral Reefs 30:283-294.

Graham NAJ, McClanahan TR, MacNeil MA, Wilson SK, Polunin NVC, Jennings S, Chabanet P, Clark S, Spalding MD, Letourneur Y et al. . 2008. Climate Warming, Marine Protected Areas and the Ocean-Scale Integrity of Coral Reef Ecosystems. PLoS ONE 3:e3039.

Grandpre D, L., Bergeron, and Y. 1997. Diversity and stability of understorey communities following disturbance in the southern boreal forest. Oxford, Royaume-Uni: Blackwell.

Grimm V, and Wissel C. 1997. Babel, or the Ecological Stability Discussions: An Inventory and Analysis of Terminology and a Guide for Avoiding Confusion. Oecologia 109:323-334.

Halford A, Cheal AJ, Ryan D, Williams DMcB. 2004. Resilience to large-scale disturbance in coral and fish assemblages on the Great Barrier Reef. Ecology 85:1892-1905.

Hughes, A. R., and J. J. Stachowicz. 2004. Genetic diversity enhances the resistance of a seagrass ecosystem to disturbance. Proceedings of the National Academy of Sciences 101:8998-9002.

Huston MA. 1985. Patterns of species diversity on coral reefs. Annual Review of Ecology and Systematics 16:149-177.

Huston MA. 1997. Hidden treatments in ecological experiments: re-evaluating the ecosystem function of biodiversity. Oecologia 110:449-460.

Idjadi, JA, SC Lee, JF Bruno, WF Precht, L Allen-Requa, and PJ Edmunds. 2006. Rapid phaseshift reversal on a Jamaican coral reef. Coral Reefs 25:209-211 
Ives AR, Cardinale BJ, and Snyder WE. 2005. A synthesis of subdisciplines: predator-prey interactions, and biodiversity and ecosystem functioning. Ecology Letters 8:102-116.

Ives AR, and Carpenter SR. 2007. Stability and Diversity of Ecosystems. Science 317:58-62.

Karlson, RH, HV Cornell, TP Hughes. 2004. Coral communities are regionally enriched along an oceanic biodiversity gradient. Nature $429,867$.

May RM. 1973. Stability and complexity in model ecosystems. Princeton: Princeton University Press.

McCann KS. 2000. The diversity-stability debate. Nature 405:228-233.

McNaughton SJ. 1977. Diversity and Stability of Ecological Communities: A Comment on the Role of Empiricism in Ecology. The American Naturalist 111:515-525.

Miller I, and Müller R. 1999. Validity and reproducibility of benthic cover estimates made during broadscale surveys of coral reefs by manta tow. Coral Reefs 18:353-356.

Naeem S. 1998. Species Redundancy and Ecosystem Reliability. Conservation Biology 12:39-45.

Naeem S, and Li S. 1997. Biodiversity enhances ecosystem reliability. Nature 390:507-509.

Pimm SL. 1984. The complexity and stability of ecosystems. Nature 307:321-326.

R Core Team. 2012. R: A Language and Environment for Statistical Computing. Vienna, Austria: R Foundation for Statistical Computing.

Reusch TBH, Ehlers A, Hammerli A, and Worm B. 2005. Ecosystem recovery after climatic extremes enhanced by genotypic diversity. PNAS \%R 101073/pnas0500008102 102:28262831.

Roberts CM, McClean CJ, Veron JEN, Hawkins JP, Allen GR, McAllister DE, Mittermeier CG, Schueler FW, Spalding M, Wells F et al. . 2002. Marine biodiversity hotspots and conservation priorities for tropical reefs. Science 295:1280-1284.

Roff G, and Mumby PJ. 2012. Global disparity in the resilience of coral reefs. Trends Ecol Evol 27:404-413. 
Schluter D. 2000. The ecology of adaptive radiation: OUP Oxford.

Selig ER, and Bruno JF. 2010. A global analysis of the effectiveness of marine protected areas in preventing coral loss. PLoS ONE 5:e9278.

Selig ER, Casey KS, and Bruno JF. 2012. Temperature-driven coral decline: the role of marine protected areas. Global Change Biology 18:1561-1570.

Stachowicz JJ, Bruno JF, and Duffy JE. 2007. Understanding the effects of marine biodiversity on communities and ecosystems. Annual Review of Ecology, Evolution, and Systematics 38:739-766.

Stachowicz JJ, Graham M, Bracken MES, and Szoboszlai AI. 2008. Diversity Enhances Cover and Stability of Seaweed Assemblages: The Role of Heterogeneity and Time. Ecology 89:3008-3019.

Steiner CF, Long ZT, Krumins JA, and Morin PJ. 2006. Population and community resilience in multitrophic communities. Ecology 87:996-1007.

Tilman D, and Downing JA. 1994. Biodiversity and stability in grasslands. Nature 367:363-365.

Veron J. 2000. Corals of the world. Australian Institute of Marine Science Townsville, Australia.

Veron J, Devantier LM, Turak E, Green AL, Kininmonth S, Stafford-Smith M, and Peterson N. 2009. Delineating the coral triangle. Galaxea, Journal of Coral Reef Studies 11:91-100.

Veron JEN. 1986. Corals of Australia and the Indo-Pacific. Sydney: Angus and Robertson.

Veron JT, E; DeVantier, LM; Stafford-Smith, MG; Kininmonth, S 2011. Coral Geographic. Version 1.1. ed: Aust. Inst. Mar. Sci.

Williams SL. 2001. Reduced genetic diversity in eelgrass transplantations affects both population growth and individual fitness. Ecological Applications 11:1472-1488.

Willis BL, Page CA, and Dinsdale EA. 2004. Coral disease on the Great Barrier Reef. In: Rosenberg E, and Loya Y, eds. Coral Health and Disease. Berlin: Springer-Verlag, 69104. 
322 Yachi S, and Loreau M. 1999. Biodiversity and ecosystem productivity in a fluctuating 323 environment: The insurance hypothesis. Proceedings of the National Academy of Sciences

324 $96: 1463-1468$. 


\section{Table 1 (on next page)}

Table 1

Linear models performed in analyses. 


\section{Linear model description -Decline}

\section{Raw data}

Richness + maxdepth + disturbance + region + blcc

Richness + maxdepth + blcc

Richness + blcc

Richness + maxdepth + disturbance + region + blcc + maxdepth:disturbance interaction

\section{Square root transformed}

Richness + maxdepth + disturbance + region + blcc $^{\dagger}$

- Intercept

- Richness

- Max depth

- Disturbance-COTS

- Disturbance - Storms

- Region - E. Pacific

- Region - Indian Ocean

- Region - W. Pacific

- $\mathrm{BLCC}$

Richness + maxdepth + blcc $* \dagger$

- Intercept

- Richness

- Max depth

- BLCC

Richness + blcc

Richness + maxdepth + disturbance + region + blcc + maxdepth:disturbance interaction
AIC $\quad \mathbf{R}^{2} \quad$ p-value

351.94

0.71

$4.04 \mathrm{e}-07$

349.46

0.65

$5.56 \mathrm{e}-09$

414.92

0.60

$2.73 \mathrm{e}-10$

354.75

0.71

2.85e-06 $\begin{array}{ll}148.77 & 0.70\end{array}$

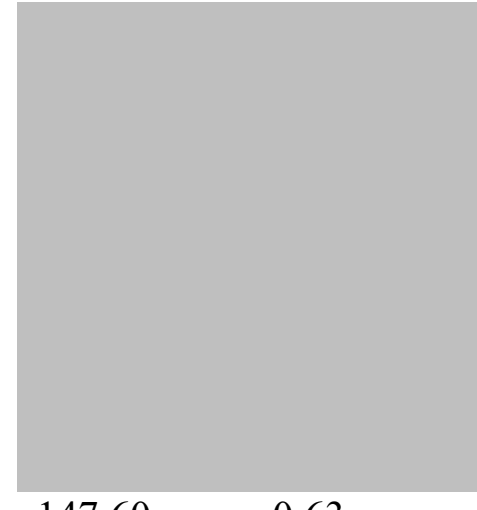

$147.60 \quad 0.63$

$5.62 \mathrm{e}-07$

0.05

0.78

0.95

0.69

0.51

0.17

0.67

0.98

$3.72 \mathrm{e}-8$

$1.50 \mathrm{e}-08$

0.15

0.03

0.61

$1.02 \mathrm{e}-08$

174.83

0.59

$6.82 \mathrm{e}-10$

150.30

0.72

\section{Linear model description - Recovery}

\section{Raw data}

Richness + maxdepth + disturbance + region + pdcc

Richness + maxdepth

Richness

\section{Log transformed}

Richness + maxdepth + disturbance + region + pdcc*

- Intercept

- Richness

- Max depth

- Disturbance-COTS

$\begin{array}{lll}\text { AIC } & \mathbf{R}^{2} & \text { p-value } \\ 264.05 & 0.27 & 0.03 \\ 264.11 & 0.12 & 0.04 \\ 274.63 & 0.062 & 0.07\end{array}$

- Disturbance - Storms

104.77

0.38

$0.04 \mathrm{e}-1$

$3.95 \mathrm{e}-06$

0.56

0.10

0.35

0.21

0.25 
- Region - Indian Ocean

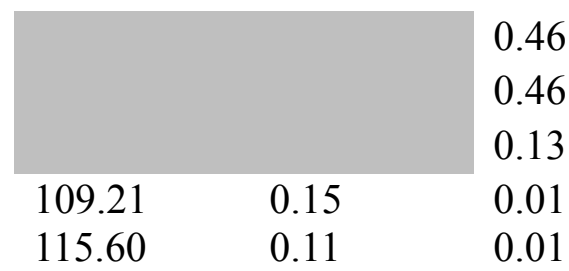

- Region - W. Pacific

- PDCC

Richness + maxdepth

Richness

115.60

0.11

0.01

Table 1. Linear models performed in analyses.

* indicates best fit model for coral cover decline and recovery based upon lowest AIC. p-values for best fit model factors listed below model description.

${ }^{\dagger}$ indicates best fit decline models which did not differ significantly based upon AIC. 


\section{Figure 1}

Coral community richness and resistance to disturbance.

3-D scatter plot of the relationship between coral community richness, coral loss (net change in absolute percent cover in response to disturbance) and initial coral cover. See Table 1 for results of statistical analysis. Dashed lines represent the regression plane, and point coloration represents region. Refer to the Statistical Supplement for a version of this figure plotted with the response variable square root transformed.

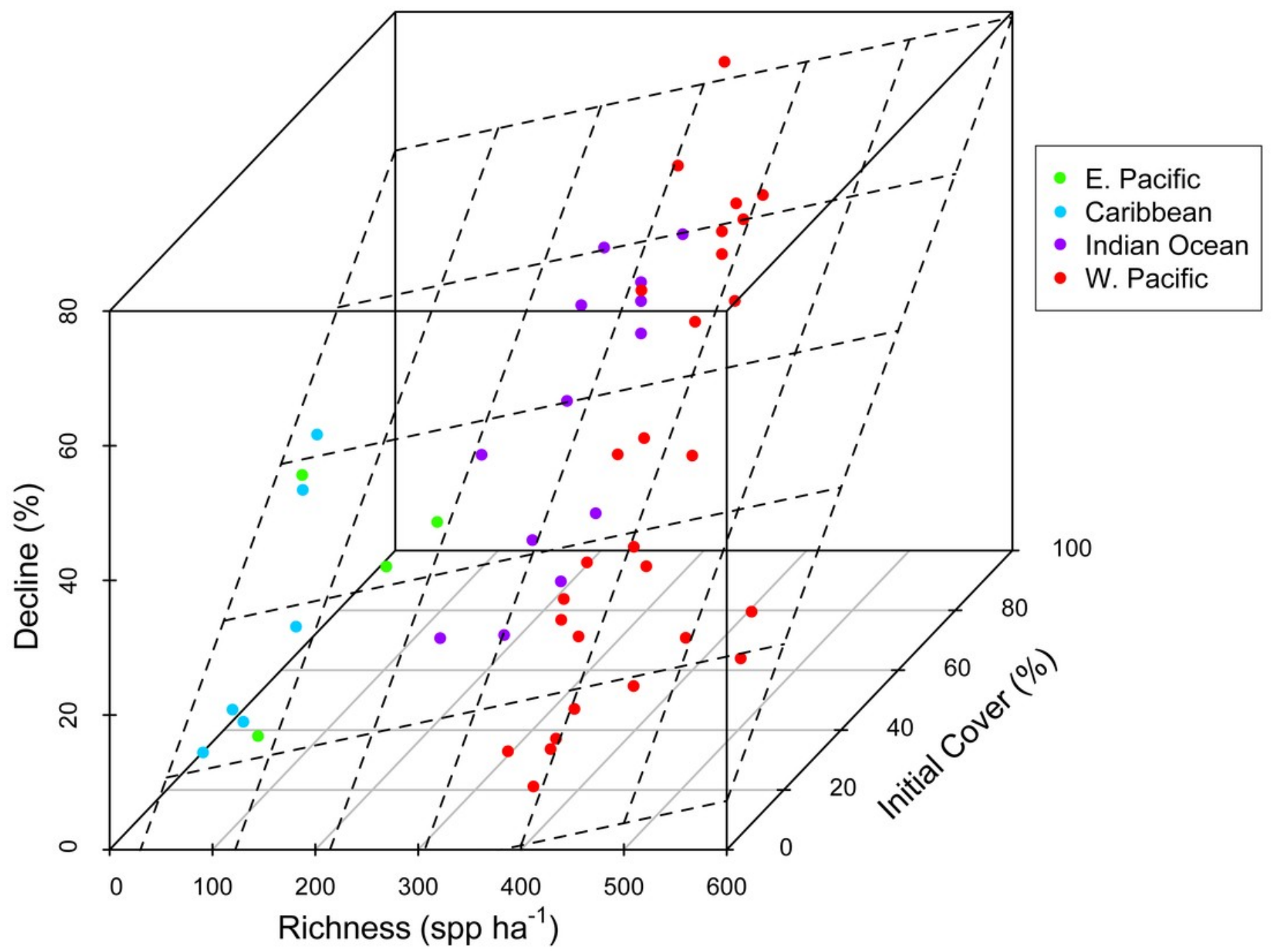




\section{Figure 2}

Coral community richness and recovery from disturbance.

Scatter plot of the relationship between the post-disturbance recovery of absolute coral cover and estimated coral species richness. Refer to the Statistical Supplement for a version of this figure plotted with the response variable log transformed.

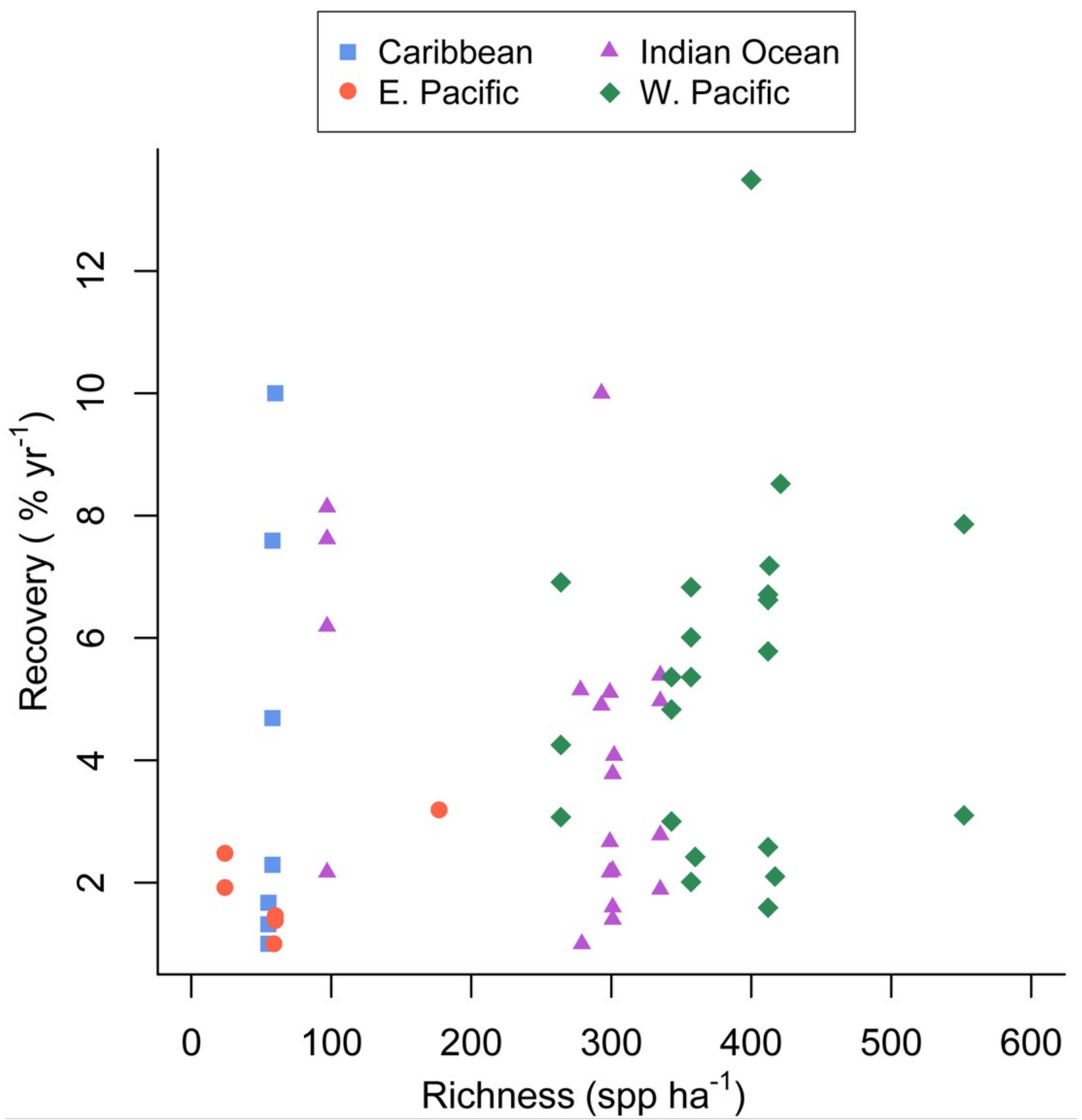

